\title{
In Situ Erosion Flume (ISEF): determination of bed-shear stress and erosion of a kaolinite bed
}

\author{
Erik-Jan Houwing *, Leo C. van Rijn \\ Institute for Marine and Atmospheric Research (IMAU), Utrecht University, P.O. Box 80.115, 3508 TC Utrecht, Netherlands
}

Received 8 July 1997; accepted 6 November 1997

\begin{abstract}
The strength of a cohesive sediment bed is difficult to determine and must be found experimentally from laboratory tests or through in situ field tests. A new in situ erosion instrument, the In situ Erosion Flume (ISEF), has been developed which is a circulating flow system in the vertical plane. The erosion process of sediment particles of the bed in the test section of the ISEF is related to the prevailing bed-shear stress induced by a unidirectional current. The bed-shear stress can be determined from the measured velocity profile in the test section assuming a logarithmic distribution in a vertical direction. The bed-shear stress equation has been calibrated under various conditions characterised by initiation of motion of sand and gravel particles at a flat bed where the bed-shear stresses mobilising the particles are known from the Shields curve. Three reproducibility tests were carried out under laboratory conditions. The bed consisted of kaolinite and was formed by sedimentation in still fresh water. The results of the three tests showed similar values. The erosion of a kaolinite sediment bed is more precisely determined under laboratory conditions by means of the ISEF. The results are compared with data from the literature. The ISEF is a relatively simple instrument for the determination of the strength of (cohesive) sediment beds. The results based on the ISEF measurements represent the minimum shear stress exerted at initiation of erosion of the bed, which will lead to the maximum shear strength of the top layer of the (cohesive) sediment bed. (C) 1998 Elsevier Science B.V. All rights reserved.
\end{abstract}

Keywords: cohesive sediments; erosion rate; shear strength; critical shear stress

\section{Introduction}

Intertidal mud flats, salt marshes and coastal wetlands in estuaries and along shallow tidal basins are important for several reasons. They host ecosystems characterised by highly specialised tidal habitats and a high productivity, and they are important bird

\footnotetext{
* Corresponding author. Present address: Institute for Inland Water Management and Waste Water Treatment, Rijkswaterstaat, van Leeuwenhoekweg 20, 3316 AV Dordrecht, The Netherlands. E-mail: e.j.houwing@riza.rws.minvenw.nl
}

refuges valuable for nature conservation. They also act as a buffer for dikes and lowlands surrounding the tidal basins. Such intertidal areas contain primarily cohesive sediment beds. Due to their relatively low level in relation to mean high tides, they will be prone to effects of sea-level rise or changes in hydrodynamic conditions. Their protection and maintenance is based on the knowledge of the effect of changing hydrodynamic conditions on the deposition of mud and sand and the erosion of the cohesive sediment beds.

Erosion of a sediment bed depends on the 
near-bed flow and the composition and resistance of the bed sediment. Cohesive sediment bottoms consist primarily of clay and fine silt, and contain varying quantities of organic matter. The clay particles are cohesive because electrochemical repulsive and attraction forces are acting between the particles. Sediments of this type are called cohesive because the sediment particles do not behave as individual discrete particles but tend to stick together forming aggregates (mud flocs) of which the size and settling velocity are much higher than that of the individual particles. Additionally, after deposition, these sediments are more resistant to erosion as the mutual attractive forces increase the strength of the bed, and higher bed-shear stresses are needed for erosion.

Migniot (1968) and Parchure and Mehta (1985) have observed that the critical bed-shear stress for erosion can be related to the sediment concentration. Complementary research, both under laboratory conditions and in the field, has shown additional influence on the ultimate strength of cohesive sediment beds through biogenic stabilisation by benthic diatoms (for instance, Holland et al., 1974; Vos et al., 1988; Grant and Daborn, 1994), by the grain-size composition or sand-mud ratio of the bed (Van Rijn, 1993; Mitchener and Torfs, 1996) and through chemical characteristics both for the eroding fluid and for the pore water and the sediment (see also Winterwerp, 1989; Berlamont et al., 1993). The strength of intertidal mud flats is strongly related to physical, biological and chemical parameters (e.g., Verreet et al., 1986; Amos et al., 1992a) and rather complex to predict. It is because of this complexity that the bedshear strength of cohesive sediments must be found experimentally from laboratory tests using natural muds (e.g. Kuijper et al., 1989), or through in situ field tests (e.g. Amos et al., 1992a,b). Although the necessity of laboratory studies has been emphasised (Dade and Nowell, 1992; Grant and Daborn, 1994) it has been observed that due to treatment, handling and storing of the samples under laboratory conditions, the sediment properties will change, resulting in higher strength of the samples than under natural conditions. Therefore, it is important that measurements of the erosive resistance of cohesive sediments are performed in situ.

Several in situ instruments are being used for erosion experiments. Amos et al. (1992a) developed a benthic annular flume in the horizontal plane (Sea Carousel) based on the principle of earlier developed laboratory carousels in which the shear stress is induced by a horizontal circulating flow. This principle has also been used by Black (1993), who developed the mobile recirculating seawater flume (MORF) for measurements of resuspension of intertidal muds. Maa et al. (1993) developed an annular sea-bed flume (VIMS) which can be deployed under deepwater conditions. Straight flumes have been reported by Young (1976) and Gust and Morris (1989).

Although the forcing of the flow of water differs for each instrument, the technique used is broadly the same, viz. a sort of field flume in which a circulating (or straight) water flow exerts a shear force on the bed surface. A disadvantage of this type of technique is the relatively large size of the instrument required to ensure a logarithmic velocity distribution. Reported sizes of the instruments are in the order of $2 \mathrm{~m}$ and the size of the test section is in the order of $0.1-1 \mathrm{~m}^{2}$.

Other techniques used for the determination of the strength of a cohesive sediment bed can be divided into: (1) generating a water jet impacting on the sediment surface (e.g. the cohesive strength meter CSM; Patterson, 1989); (2) generating turbulent motion of the water column above the sediment surface by oscillation of a horizontal grid (e.g. shaker; Tsai and Lick, 1986); (3) inducing turbulent motion by a propeller at close range above the bed surface (EROMES; Schünemann and Kühl, 1991); and (4) generating a stream of water between an inverted bell-shaped funnel, placed at close range above the sediment surface (ISIS; Williamson, 1994). A great advantage is that instruments of this type are small and therefore easy to handle. The test surface of these instruments is relatively small (in the order of 0.01 $\mathrm{m}^{2}$ and smaller) so that the results are highly dependent on small-scale irregularities of the bed surface and the settings of the instrument on the bed surface. Disadvantages are therefore primarily found in the distribution of the bottom-shear stress which is often not quite regular in time and space. Therefore, the ideal in situ instrument should be light and small, but have a relatively large test surface (of at least $0.1 \mathrm{~m}^{2}$ ).

The shear strength of cohesive sediment beds in the salt marshes along the Dutch Wadden Sea is best determined by using the principle of the rotation 
of the water flow. Most existing instruments are oriented in the horizontal plane. To avoid secondary flow patterns, these instruments are rather large and unwieldy. We have now developed a new in situ erosion instrument based on a circulating flow of water in the vertical plane. This has allowed us to reduce the dimension of the instrument, which makes it relatively light and easier to use.

This article describes the development and calibration of the erosion instrument under laboratory conditions. Its reproducibility was tested. Finally, the instrument was tested in the laboratory on a kaolinite bed and the results compared with those of other laboratory studies reported in the literature.

\section{Description of the In Situ Erosion Flume}

The In Situ Erosion Flume (ISEF) is a circulating flow system in the vertical plane. It consists of a lower horizontal test section, two bent sections and an upper section where the flow is generated by a propeller (Fig. 1).

The horizontal test section and the two bent sections have a rectangular cross-section $0.1 \mathrm{~m}$ high and $0.2 \mathrm{~m}$ wide. The bottom part of the horizontal test section is open over a length of $0.9 \mathrm{~m}$. When the ISEF is resting properly on the sediment bed, the surface of the bed will be in line with the thin steel bottom plates of the flume on both ends of the horizontal section.

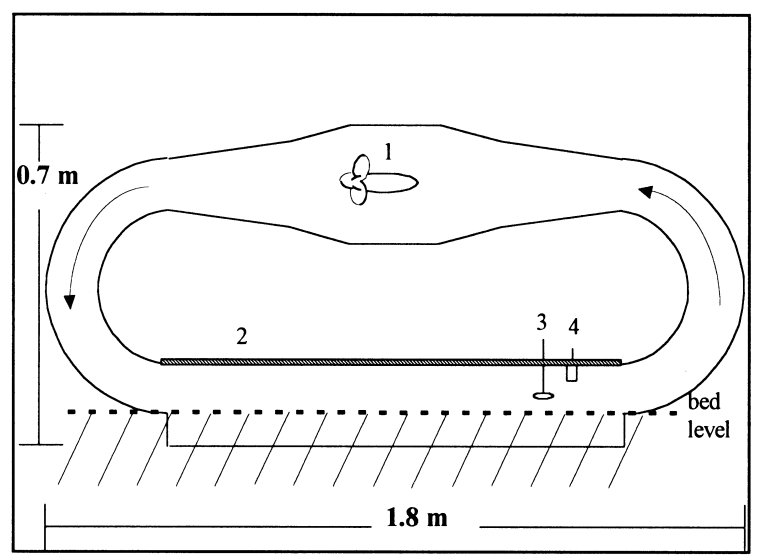

Fig. 1. A schematic drawing of the In Situ Erosion Flume (ISEF). With (1) the propeller, (2) the perspex coverplate, (3) the electromagnetic flow meter (EMF) and (4) the turbidity meter (MEX).
The total weight of the flume is $\sim 50 \mathrm{~kg}$. The total volume of water in the flume is $100 \mathrm{dm}^{3}$.

The propeller can be rotated at various speeds by means of an adjustable oil-pressure system. The flow velocity in the horizontal test section is measured by means of a small disc-type electromagnetic flow meter (EMF). The disc has a diameter of $0.033 \mathrm{~m}$ and a thickness of $0.011 \mathrm{~m}$. The centre of the measuring volume is located $2 \mathrm{~mm}$ below the disc.

The suspended-sediment concentration in the ISEF is measured by an optical sensor (MEX). This sensor contains two 880-nm light diodes (IREDs) and two silicon photodiodes, placed in the opposite direction to one another and mounted in a plastic tube. The measuring volume between the four diodes is about $1.5 \mathrm{~cm}$. The measuring method is based on the attenuation of the infrared light beam, caused by light absorption and reflection due to the presence of suspended particles in the measuring volume.

\section{Determination of the bed-shear stress}

\subsection{Basic formulae}

The erosion process of sediment particles of the bed is related to the prevailing bed-shear stress.

The bed-shear stress can be determined from the measured velocity profile assuming a logarithmic distribution in vertical direction, which reads as:

$u_{z}=\frac{u_{*}}{\kappa} \ln \left(\frac{z}{z_{0}}\right)$

in which:

$u_{z}=$ flow velocity at height $z$ above the bed $\left(\mathrm{m} \mathrm{s}^{-1}\right)$

$u_{*}=\left(\left(\tau_{\mathrm{b}}\right) /(\rho)\right)^{0.5}=$ bed-shear velocity $\left(\mathrm{m} \mathrm{s}^{-1}\right)$

$\tau_{\mathrm{b}}=$ bed-shear stress $\left(\mathrm{N} \mathrm{m}^{-2}\right)$

$z=$ height above the bed (m)

$z_{0}=0.033 k_{\mathrm{s}}+0.11 v / u_{*}=$ zero-velocity level (m)

$k_{\mathrm{s}}=$ effective roughness of Nikuradse (m)

$\kappa=$ constant of von Karman (0.4) (-)

$v=$ kinematic viscosity coefficient $\left(\mathrm{m}^{2} \mathrm{~s}^{-1}\right)$

$\rho=$ fluid density $\left(\mathrm{kg} \mathrm{m}^{-3}\right)$

Based on Eq. 1 the bed-shear stress can be expressed as:

$\tau_{\mathrm{b}}=\rho \kappa^{2} u_{z}^{2}\left[\ln \left(\frac{z}{z_{0}}\right)\right]^{-2}$

The velocity distribution in the horizontal test section is asymmetrical due to the presence of the bent 
upstream resulting in relatively large velocities in the outer part of the bend. Redistribution of the velocity profile may take place in the horizontal section. A full equilibrium flow will not be established in the ISEF because of the relatively short test section $(0.9 \mathrm{~m})$. This means that the velocity distribution in the near-bed region of the horizontal section might deviate slightly from the logarithmic distribution. Introducing a calibration coefficient $\alpha$ (close to unity) to account for this effect, and using the maximum velocity $u_{\mathrm{m}}$ at the upper edge of the boundary layer $(\delta)$ above the bed, Eq. 2 can be expressed as:

$$
\begin{aligned}
\tau_{\mathrm{b}} & =\rho \kappa^{2}\left(\alpha u_{\mathrm{m}}\right)^{2} \\
& \times\left[\ln \left(\frac{\delta}{0.033 k_{\mathrm{s}}+0.11 v\left(\tau_{b} / \rho\right)^{-0.5}}\right)\right]^{-2}
\end{aligned}
$$

\subsection{Experimental set-up}

The bed-shear stress equation was calibrated under various conditions characterised by initiation of motion of sand and gravel particles at a flat bed. The bed-shear stresses mobilising the particles are known from the Shields curve (Fig. 2 Fig. 1). A layer of sediment particles of known grain size was placed in the test section of the ISEF. The surface at the bed was flattened in such a way that the bed level lay exactly in line with the bottom plates of the ISEF.
Three stages of particle motion as defined in Fig. 2 were considered: stages 1,3 and 5. During each stage, the velocity profile in the vertical plane was measured by means of the EMF. The EMF was connected to a vertical positioning system accurate to $0.0005 \mathrm{~m}$. The height of the velocity measurements was increased with steps of $0.005 \mathrm{~m}$.

The flow velocity in the ISEF was increased until particle movement was observed by means of an underwater camera. The camera was resting on the transparent (perspex) cover plate of the test section. Four size classes of sediment were tested (Table 1). The water temperature during the test procedure was about $10^{\circ} \mathrm{C}$.

To obtain information on the vertical velocity distribution over the full range of conditions up to 2 $\mathrm{m} \mathrm{s}^{-1}$, velocity profiles were measured above a flat

Table 1

The characteristic particle diameters of the sediment material of the four types used

\begin{tabular}{lcrr}
\hline Sediment type & \multicolumn{3}{c}{ Particle size $(\mu \mathrm{m})$} \\
\cline { 2 - 4 } & $d_{10}$ & $d_{50}$ & \multicolumn{1}{c}{$d_{90}$} \\
\hline 1 & 220 & 280 & 320 \\
2 & 480 & 680 & 815 \\
3 & 650 & 890 & 1300 \\
4 & 1030 & 1820 & 3770 \\
\hline
\end{tabular}

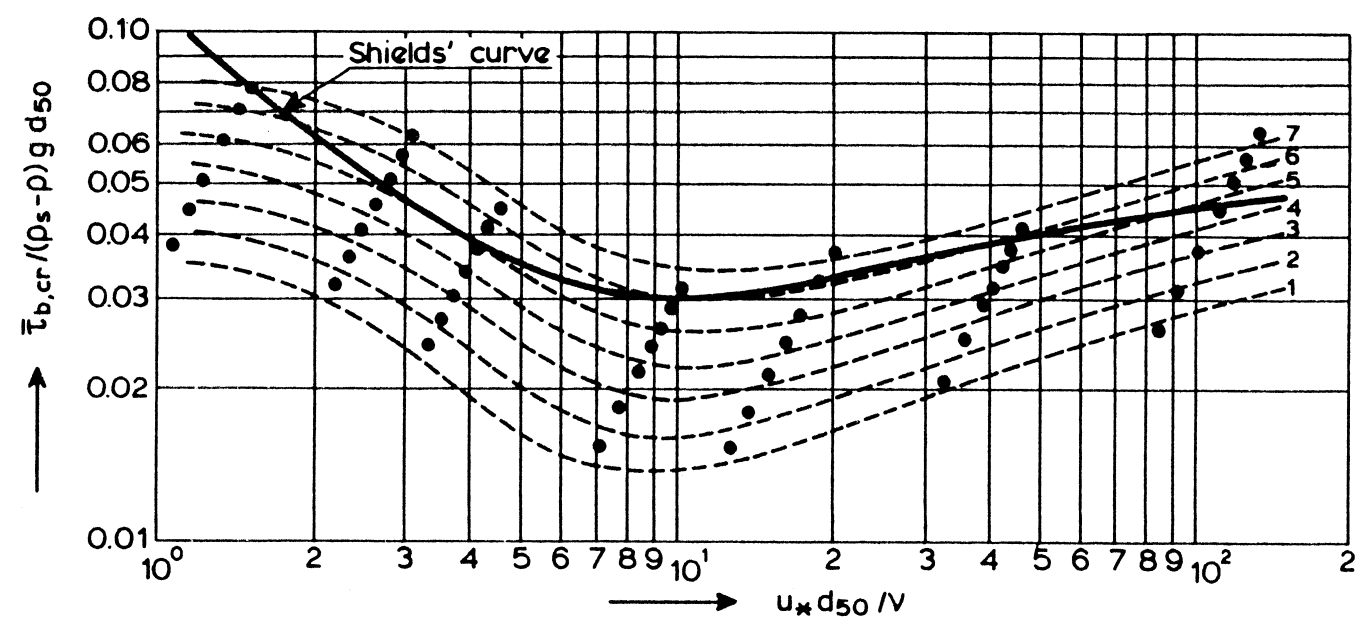

Fig. 2. Initiation of motion and suspension for a current over a plane bed, presented by the critical Shields parameter as function of the Reynolds number (Van Rijn, 1993). •, measured; 1, occasional particle movement at some locations; 2, frequent particle movement at some locations; 3 , frequent particle movement at many locations; 4 , frequent particle movement at nearly all locations; 5 , frequent particle movement at all locations; 6 , permanent particle movement at all locations; 7, general transport (initiation of ripples). 
rigid bed consisting of non-movable particles of 100 $\mu \mathrm{m}$.

\subsection{Analysis results}

The velocity measurements above the flat bed of moving particles were carried out at conditions just beyond initiation of motion. The velocity profiles measured above the movable bed are presented in Fig. 3. Repeated measurements above the movable bed as well as above the rigid non-movable bed showed maximum variations of about $5 \%$, which were probably related to variations of the propeller circulating the flow.

The thickness of the bottom boundary layer $(\delta)$ was defined by the height where the maximum current velocity is found. Based on the measured velocity profiles, this height was found to be about 0.025 $\mathrm{m}$ above the sediment bed (Fig. 3).

The velocity profiles measured at $0.55 \mathrm{~m}$ from the
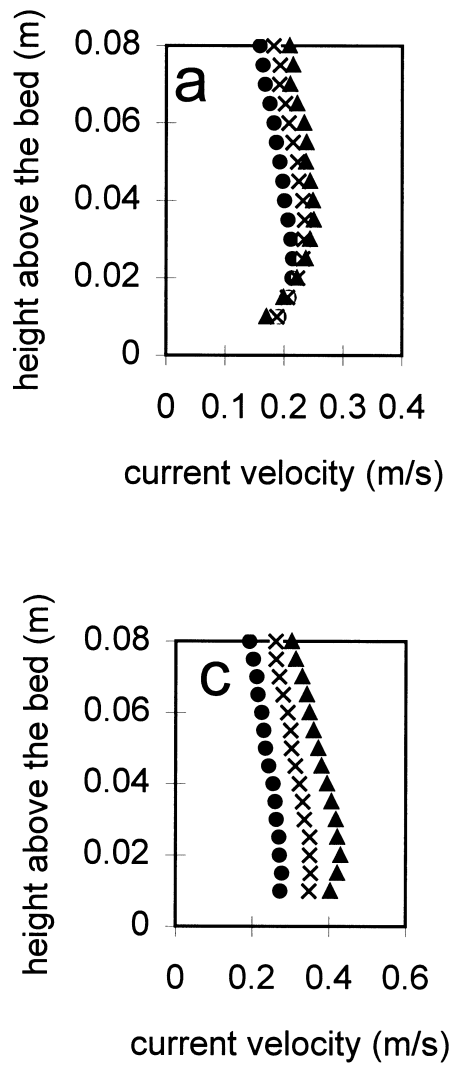

entrance of the test section showed a dip in the upper part of the profile. The reason for this dip is not yet clear. It is recommended to perform more detailed velocity measurements at more locations using a hotfilm anemometer or a laser-Doppler velocity meter.

The critical bed-shear stresses $\left(\tau_{\mathrm{b}, \mathrm{cr}}\right)$ corresponding to stages 1, 3 and 5, as obtained from Fig. 2, are presented in Table 2. The relative inaccuracy of the critical bed-shear stress was about $20 \%$, due to the variations in the 'maximum' velocity obtained at the edge of the boundary layer with deviations of \pm 0.01 (m).

The $\alpha$-coefficient can be computed from Eq. 3, yielding:

$$
\begin{aligned}
\alpha= & \left(\kappa u_{\mathrm{m}}\right)^{-1}\left(\frac{\tau_{\mathrm{b}, \mathrm{cr}}}{\rho}\right)^{0.5} \\
& \times \ln \left(\frac{\delta}{0.033 d_{90}+0.11 v\left(\tau_{\mathrm{b}, \mathrm{cr}} / \rho\right)^{-0.5}}\right)
\end{aligned}
$$
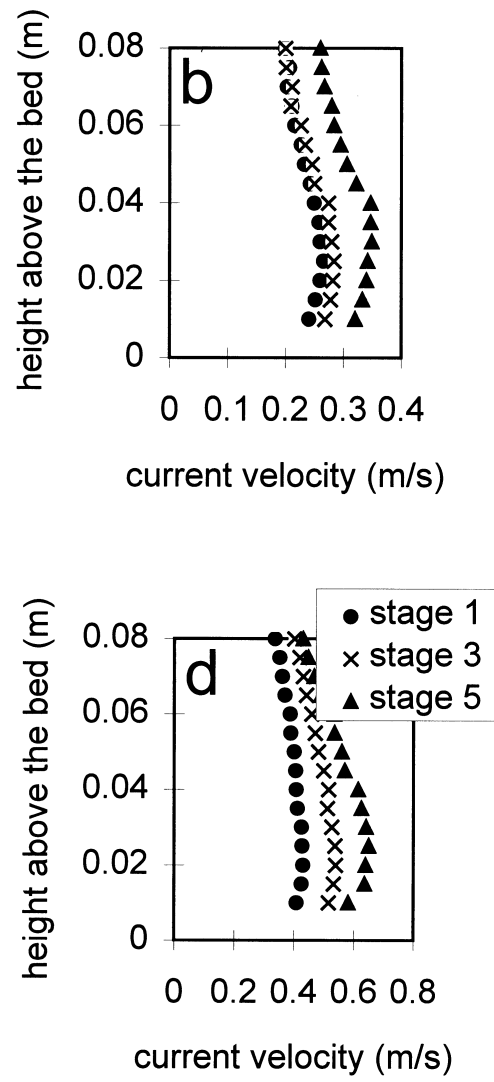

Fig. 3. Velocity profiles above a movable bed for sediment types 1 (a), 2 (b), 3 (c), and 4 (d). 
Table 2

The maximum velocity $\left(u_{\mathrm{m}}\right)$ measured at $z=\delta$, the corresponding boundary layer thickness $(\delta)$ and the critical bed-shear stress $\left(\tau_{\mathrm{b}, \mathrm{cr}}\right)$ obtained from Fig. 2, for four types of sediment and three stages (1,3 and 5) as specified in Fig. 2

\begin{tabular}{lllll}
\hline Stage & \multicolumn{4}{l}{ Sediment type } \\
\cline { 2 - 5 } & 1 & 2 & 3 & 4 \\
\hline \multicolumn{4}{l}{$u_{\mathrm{m}}\left(\mathrm{m} \mathrm{s}^{-1}\right)$} \\
1 & 0.21 & 0.26 & 0.28 & 0.43 \\
3 & 0.23 & 0.28 & 0.35 & 0.54 \\
5 & - & 0.34 & 0.43 & 0.64 \\
$\delta(\mathrm{m})$ & & & & \\
1 & 0.03 & 0.03 & 0.02 & 0.02 \\
3 & 0.03 & 0.03 & 0.02 & 0.02 \\
5 & - & 0.03 & 0.02 & 0.03 \\
& & & & \\
$\tau_{\mathrm{b}, \mathrm{cr}}\left(\mathrm{N} \mathrm{m}{ }^{-2}\right)$ & $0.12 \pm 0.02$ & $0.15 \pm 0.03$ & $0.19 \pm 0.04$ & $0.60 \pm 0.10$ \\
3 & $0.15 \pm 0.02$ & $0.21 \pm 0.03$ & $0.27 \pm 0.04$ & $0.80 \pm 0.10$ \\
5 & - & $0.27 \pm 0.03$ & $0.35 \pm 0.04$ & $1.00 \pm 0.10$ \\
\hline
\end{tabular}

where $\tau_{\mathrm{b}, \mathrm{cr}}=$ the known critical bed-shear stress ( $\mathrm{N}$ $\mathrm{m}^{-2}$ ) based on the Shields curve (Table 2), $u_{\mathrm{m}}=$ the measured velocity $\left(\mathrm{m} \mathrm{s}^{-1}\right.$ ) (Table 2) at $z=\delta=$ $0.025(\mathrm{~m})$ above the bed, assuming $k_{\mathrm{s}}=d_{90}(\mathrm{~m})$ for a flat bed, $\kappa=0.4(-), \rho=1000\left(\mathrm{~m}^{2} \mathrm{~s}^{-1}\right)$ and $v=1.3110^{-6}\left(\mathrm{~kg} \mathrm{~m}^{-3}\right)$ at the temperature of $10^{\circ} \mathrm{C}$. Although the experiment was based on the use of non-cohesive (sand) sediments only, it is assumed that in cohesive sediments, which mostly show flat bed profiles, the flow will be in the smooth regime and the relationship between the $u_{\mathrm{m}}$ and $\tau_{\mathrm{cr}}$ will not change. The results are shown in Fig. 4. The computed $\alpha$-coefficients showed a decreasing trend with the particle Reynolds number $\left(u_{*} k_{\mathrm{s}} / v\right)$. The inaccuracy of the $\alpha$-coefficient is \pm 0.1 , presented as a vertical bar (Fig. 4).

The hydraulic flow regime as a function of Reynolds number is given by:

Hydraulic smooth for $\frac{u_{*} k_{\mathrm{s}}}{v} \leq 5$

Hydraulic transition for $5<\frac{u_{*} k_{\mathrm{s}}}{v}<70$

Hydraulic rough for $\frac{u_{*} k_{\mathrm{s}}}{v} \geq 70$

In the case of the smooth flow regime, an $\alpha$-coefficient of 0.9 is recommended.

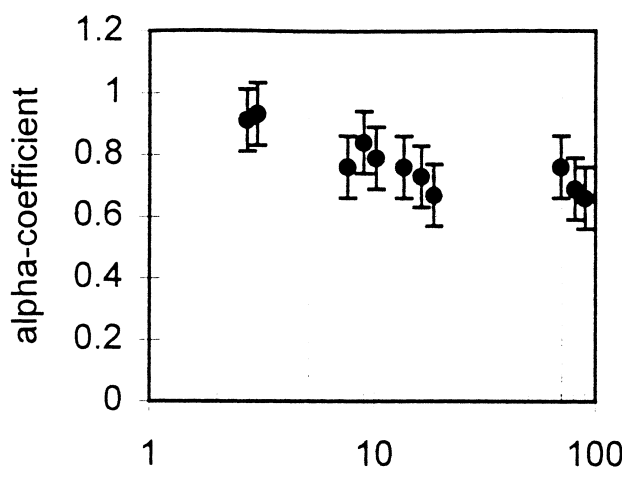

Particle Reynolds number

Fig. 4. The computed $\alpha$-coefficients plotted against the particle Reynolds numbers $\left(\mathrm{Re}_{*}\right)$ on a $\log$ scale for a hydraulic smooth regime at $\mathrm{Re}_{*}<5$, a hydraulic transition regime when $5<\mathrm{Re}_{*}<70$, and a hydraulic rough regime at $\mathrm{Re}_{*} \geq 70$.

\section{Reproducibility measurements}

Reproducibility tests are essential for a correct interpretation of in situ field measurements. Changes in test results should be due to changes in bed composition rather than to differences in the settings of the instrument. It is expected that with the ISEF, erosion will appear more easily along the edges of the test section because here the bed might be slightly disturbed. Besides, small undulations on top of the sediment bed can lead to fluctuations in the velocity profile resulting in variations of the shear stress as obtained from Eq. 3.

To investigate the reproducibility error of the ISEF, three laboratory tests were carried out. For each test, a new sediment bed was constructed in the test section of the ISEF. The bed consisted of kaolinite and was formed by sedimentation in still fresh water. The mean density of the kaolinite bed was in the order of $350 \mathrm{~kg} \mathrm{~m}^{-3}$. The water temperature was about $10^{\circ} \mathrm{C}$.

The current velocity in the ISEF was increased in steps of $1 \mathrm{~h}$ during each experiment. The sediment concentrations were measured by means of the optical sensor at $0.05 \mathrm{~m}$ above the bed at the end of the test section.

Fig. 5 shows increasing concentrations as a function of the flow velocity above the test section. The results of the three ISEF tests showed similar values. Initiation of erosion of the kaolinite bed started 


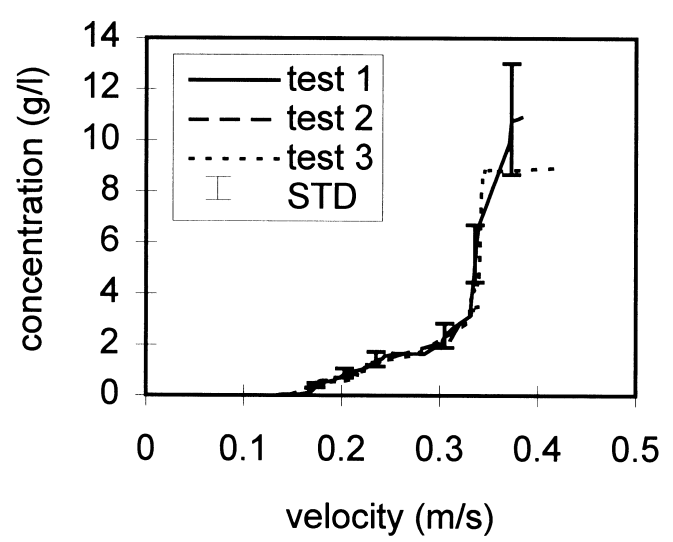

Fig. 5. Reproducibility of three erosion tests performed by the ISEF, showing an increase in suspended concentration (erosion of the kaolinite bed) at an increase of the applied current velocity.

around $0.15 \mathrm{~m} \mathrm{~s}^{-1}\left(0.05 \mathrm{~N} \mathrm{~m}^{-2}\right)$. Erosion proceeded under the higher velocities and stresses applied.

The standard deviation of the three ISEF test results was estimated to be $\sim 20 \%$. Only at high stresses (current velocity $>0.4 \mathrm{~m} \mathrm{~s}^{-1}$ or stresses $>0.23 \mathrm{~N} \mathrm{~m}^{-2}$ ) did the standard deviation increase to values $>50 \%$. This might be due to the generation of erosion holes resulting in additional turbulence above the bed yielding higher variations in stresses.

Cornelisse et al. (1994) found that the areal size of the test section is crucial for the reproducibility of the erosion instruments. The spatial variations in the bed properties and the turbulent stresses are averaged out when the erodible area is larger. They found a linear relationship between the standard deviation of the repeated measurements and the areal surface which reads as: $R=800^{*} A^{-0.5}$, based on 13 tests carried out with four different erosion instruments. The surface area of the test section of the ISEF measures $1800 \mathrm{~cm}^{2}$ and the resulting error $R$ is calculated to be $\sim 15 \%$, which is in agreement with the results of the reproducibility test reported above.

\section{Erosion of a kaolinite bed}

\subsection{Introduction}

The erosion of a kaolinite sediment bed was determined under laboratory conditions by means of the ISEF and compared with data from Parchure and Mehta (1985) and Kuijper et al. (1989). Parchure and Mehta (1985) have shown that a consolidated kaolinite bed is generally characterised by a critical strength against erosion increasing with depth beneath the bed surface. In this case, the erosion rate of a non-homogeneous bed can be represented by the function:

$E=E_{\mathrm{f}} e^{\left[\gamma\left(\tau_{\mathrm{b}}-\tau_{\mathrm{s} z z}\right)^{0.5}\right]}$

where $E=$ erosion rate $\left(\mathrm{kg} \mathrm{m}^{-2} \mathrm{~s}^{-1}\right), E_{\mathrm{f}}=$ floc erosion rate $\left(\mathrm{kg} \mathrm{m}^{-2-1}\right), \gamma=$ factor $\left(\mathrm{m} \mathrm{N}^{-0.5}\right), \tau_{\mathrm{b}}=$ applied bed stress $\left(\mathrm{N} \mathrm{m}^{-2}\right)$ and $\tau_{\mathrm{s}, z}=$ bed strength at depth $z$ beneath the bed surface $\left(\mathrm{N} \mathrm{m}^{-2}\right)$.

Erosion of the kaolinite bed in the test section of the ISEF is found as long as the bed-shear stress $\left(\tau_{\mathrm{b}}\right)$ exerted by the current velocity in the ISEF is larger than the shear strength $\left(\tau_{\mathrm{s}}\right)$ of the top layer of the kaolinite bed. Erosion of the bed is arrested when the strength of the newly exposed top layer of the bed is equal to or overcomes the shear stress applied. This can be observed from the development of the sediment concentration in time, as follows: $\tau_{\mathrm{b}}>\tau_{\mathrm{s}}$ if $\mathrm{d} c / \mathrm{d} t \gg 0$, and $\tau_{\mathrm{b}} \leq \tau_{\mathrm{s}}$ if $\mathrm{d} c / \mathrm{d} t \approx 0$, where $\mathrm{d} c$ is the observed change in suspended sediment concentration in the ISEF and $\mathrm{d} t$ is the change in time.

\subsection{Test procedure}

The sediment bed in the test section consisted of kaolinite and was formed by sedimentation in still water. The initial concentration was $500 \mathrm{~kg} \mathrm{~m}^{-3}$. The initial thickness of the bed was $0.06 \mathrm{~m}$. After 6 days' consolidation, the kaolinite bed was $0.05 \mathrm{~m}$ thick and the top of the bed was exactly in line with the bottom plates of the test section.

The density of the kaolinite bed was determined with a conductivity concentration meter (CCM). The CCM consisted of four small electrodes, each with a diameter of $0.3 \mathrm{~mm}$ and placed $0.6 \mathrm{~mm}$ from each other. The electrodes measured the change in resistance for changes in fluid-sediment mixtures. The height of the measuring volume was $1 \mathrm{~mm}$. To improve the sensitivity of the instrument, $10 \mathrm{~g}$ salt on $5 \mathrm{dm}^{3}$ water was added during the present calibration for kaolinite material (Fig. 6).

The suspended sediment concentration in the ISEF was measured with an optical sensor. The position of the sensor was fixed at $0.65 \mathrm{~m}$ from the 


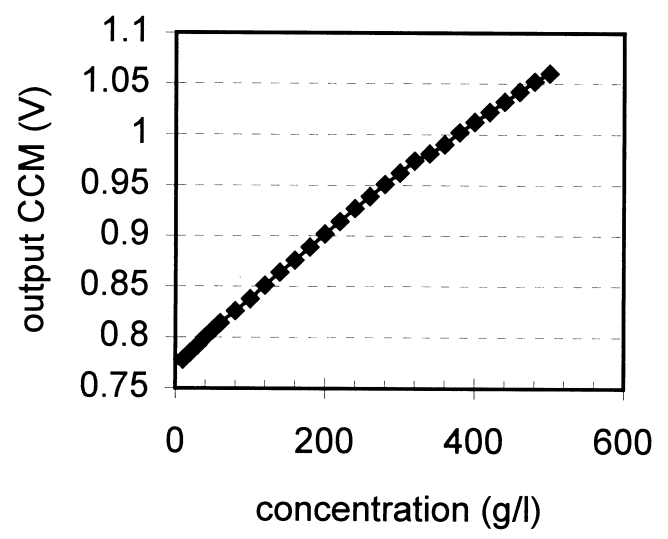

Fig. 6. The calibration curve for the conductivity concentration meter (CCM) showing the relationship between the registration by the CCM (output in $\mathrm{V}$ ) and the concentration of kaolinite.

entrance of the test section. The measuring volume was $0.01 \mathrm{~m}$ below the cover plate, which was about $0.09 \mathrm{~m}$ above the bed surface. During the experiment, the output of the optical sensor was visualised directly on the computer screen. The calibration of the optical sensor was based on water samples pumped during the test procedure.

Current velocity in the ISEF was increased in steps. First, it was increased until erosion of the bed was observed. It was then kept constant, maintaining a constant shear stress acting on the sediment bed (first step). The length of this (and any following) step was defined by erosion of the bed $\left(\tau_{\mathrm{b}}>\tau_{\mathrm{s}} ; \mathrm{d} c / \mathrm{d} t>0\right)$ until erosion stopped $\left(\tau_{\mathrm{b}} \leq \tau_{\mathrm{s}}\right.$; $\mathrm{d} c / \mathrm{d} t=0)$. Subsequently, current velocity was increased anew until erosion was again observed, and the velocity was kept constant for some time (the next step).

\subsection{Results}

The density of the kaolinite bed after consolidation is presented in Fig. 7. The bed density increased as a function of depth. A good description can be found by means of the power function:

$\frac{\rho}{\bar{\rho}}=\alpha z^{\beta}$

where $\rho$ is the concentration $\left(\mathrm{kg} \mathrm{m}^{-3}\right)$ at depth $z(\mathrm{~m})$, $\bar{\rho}$ is the mean depth concentration $\left(514 \mathrm{~kg} \mathrm{~m}^{-3}\right), \alpha$ is a factor with a value of $2.95 \mathrm{~m}^{-1}$ and $\beta$ an exponent with a value of $0.26(-)$.

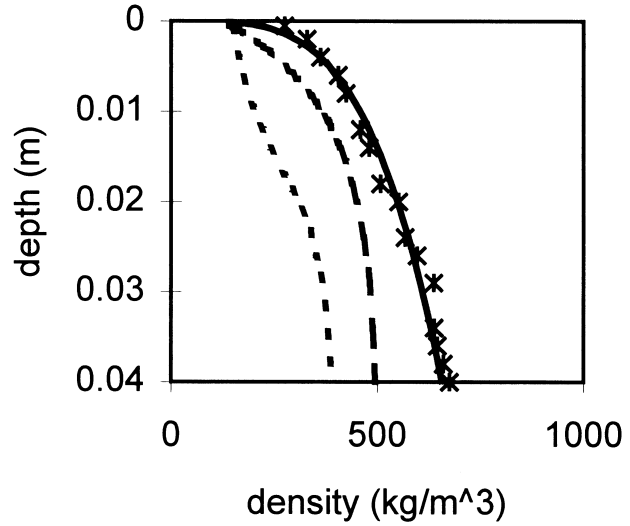

Fig. 7. Bed-density profiles as function of depth, measured by the conductivity concentration meter (asterisks). — test, calculated with Eq. 6; ---, from Kuijper et al. (1989); ----, from Parchure and Mehta (1985).

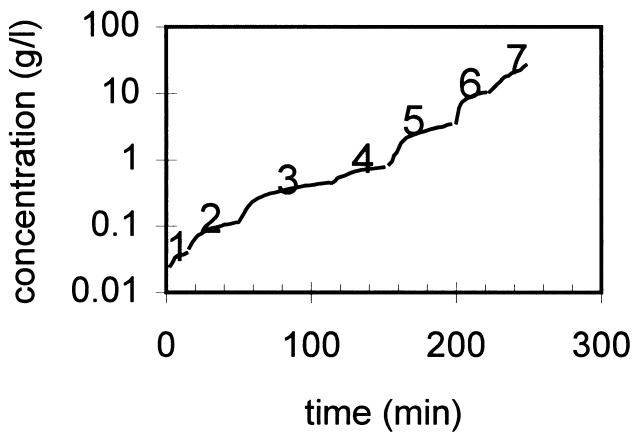

Fig. 8. Time course of the sediment concentrations measured in the ISEF over seven stages (1-7) of erosion with increasing current velocity.

During the test procedure, seven steps of erosion with increasing sediment concentrations were established (Fig. 8). The first five steps represented erosion of the sediment bed as a continuously decreasing function with time after an initial rapid increase. Only at the last two stages did the higher stresses generate a linear or quasi-linear erosion pattern. Similar findings have been reported by other authors under laboratory experiments (e.g. Mehta and Partheniades, 1982; Kuijper et al., 1989) as well as during in situ field experiments (e.g. Amos et al., 1992a,b).

The erosion rate as function of the excess shear stress $\left(\tau_{\mathrm{b}}-\tau_{\mathrm{s}}\right)^{0.5}$ is shown in Fig. 9. According to Eq. 5, the coefficients in the erosion rate expression were calculated to be $E_{\mathrm{f}}=5.810^{-5}\left(\mathrm{~kg} \mathrm{~m}^{-2} \mathrm{~s}^{-1}\right)$ 


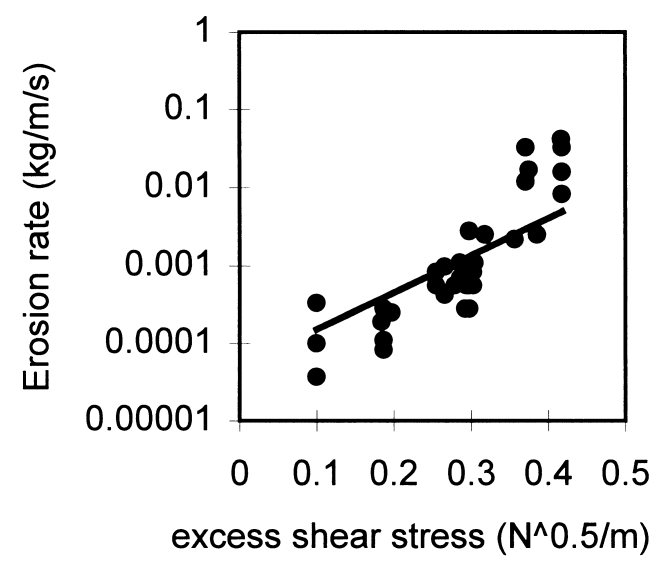

Fig. 9. Erosion rate against the excess shear stress as derived from time series in Fig. 8. The points denote separate measurements, the line represents Eq. 5, see text.

and $\gamma=11\left(\mathrm{~m} \mathrm{~N}^{-0.5}\right)$. The value of the floc erosion rate $E_{\mathrm{f}}$ was an order of magnitude higher than reported by Parchure and Mehta (1985) and Kuijper et al. (1989) (Table 3) and may have been due to differences in the density as function of depth.

Assuming that erosion of the bed is equally distributed throughout the surface area, the erosion depth obtained at the end of each erosion step (1-7) follows from the change in the suspended concentration during each step in combination with the dry density profile according to Eq. 6. The subsequent erosion steps (1-7) show an increase in erosion depth as a function of the shear stress applied with each step. Connecting the discrete points will give the shear strength profile (Fig. 10).

The strength profiles as found by Parchure and Mehta (1985) and Kuijper et al. (1989) show lower values than the one constructed from the ISEF measurements (Fig. 10). It is commonly accepted that higher values of bed-shear stress are needed for ero-

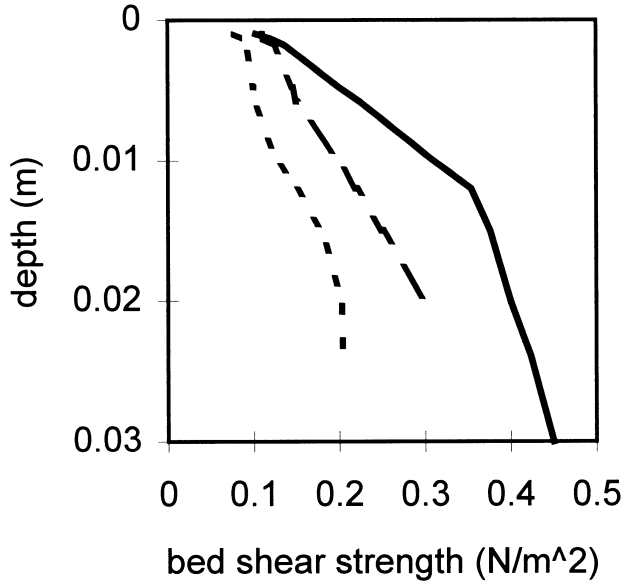

Fig. 10. The bed-shear strength as a function of depth going with the bed density profiles from Fig. 7. this test (see text); ---, from Kuijper et al. (1989); ---, from Parchure and Mehta (1985).

sion of sediment beds with increasing bed densities. In this respect the higher bed-strength profiles are most likely related to the observed higher values of the bed density profiles (see Fig. 7).

\section{Conclusions and recommendations}

The following conclusions are made:

(1) The bed-shear stress can be computed from Eq. 4 using the velocity measured at $0.025 \mathrm{~m}$ above the bed with an inaccuracy of about $20 \%$.

(2) The velocity distribution over the depth in the horizontal section is asymmetrical because of the presence of the bent upstream of the horizontal section. An $\alpha$-coefficient is introduced to account for this effect.

(3) The calibration coefficient $(\alpha)$ is related to the Reynolds number $\left(u_{*} k_{\mathrm{s}} / v\right)$ according to Fig. 4;

Table 3

Values for $\gamma$, the floc erosion rate $\left(E_{\mathrm{f}}\right)$, and the range of the bed density $(\rho)$, as found in five different studies

\begin{tabular}{lllll}
\hline Sediment & Reference & $\begin{array}{l}E_{\mathrm{f}} \times 10^{-6} \\
\left(\mathrm{~m} \mathrm{~N}^{-0.5}\right)\end{array}$ & $\begin{array}{l}\rho \\
\left(\mathrm{kg} \mathrm{m}^{-3}\right)\end{array}$ \\
\hline Kaolinite in salt water & Parchure and Mehta (1985) & 17.2 & 2.3 & $150-400$ \\
Kaolinite in fresh water & Parchure and Mehta (1985) & 18.4 & 0.8 & $?$ \\
Kaolinite & Dixit (1982) & 25.6 & 1.0 & $?$ \\
Kaolinite in salt water & Kuijper et al. (1989) & $12-28$ & $0.3-3.3$ & $150-500$ \\
Kaolinite in salt water & present study & 11 & 58 & $275-675$ \\
\hline
\end{tabular}


a value of $\alpha=0.9$ is recommended for the smooth flow regime.

(4) The laboratory experiments of the ISEF show realistic results compared to the findings of other researchers.

(5) The laboratory experiments show that the reproducibility of the ISEF is reasonably good (within $20 \%)$.

(6) The ISEF is a relatively simple instrument for the determination of the strength of sediment beds. The results based on the ISEF measurements represent the minimum shear stress exerted at initiation of erosion of the bed that will lead to the maximum shear strength of the top layer of the sediment bed.

It is recommended to measure velocity fluctuations and bed-shear stresses in the near-bed region of the horizontal section with a hot-film velocity meter or a laser-Doppler velocity meter in laboratory conditions. This may lead to a more precise description of the shear stress exerted on the bed.

\section{Acknowledgements}

We gratefully acknowledge the help of $\mathrm{T}$. van Maar for assistance in carrying out the testing and calibration of the ISEF. The construction of the ISEF was co-sponsored by Delft Hydraulics and Rijkswaterstaat. This project was carried out within the framework of the first stage of the Dutch National Research Programme on Global Air Pollution and Climatic Change (NRP I, 1990-1995).

\section{References}

Amos, C.L., Daborn, G.R., Christian, H.A., 1992a. In-situ erosion measurements on fine-grained sediments from the Bay of Fundy. Mar. Geol. 108, 175-196.

Amos, C.L., Grant, J., Daborn, G.R., Black, K., 1992b. Sea Carousel - a benthic, annular flume. Est. Coast. Shelf Sci. 34, 557-577.

Berlamont, J., Ockenden, M., Toorman, E., Winterwerp, J., 1993. The characterisation of cohesive sediment properties. Coast. Eng. 21, 105-128.

Black, K., 1993. The turbulent resuspension of cohesive intertidal muds: some new concepts and ideas. In: Sterr, H., Hofsede, J., Plag, H.-P. (Eds.), Proceedings of the International Coastal Congress ICC-Kiel '92. Peter Lang, Berlin, pp. 223-239.

Cornelisse, J.M., Mulder, H.P.J., Williamson, H., Witte, G., Houwing, E.J., 1994. On the development of instruments for in situ erosion measurements. 4th Nearshore and Estuarine
Cohesive Sediment Transport Conference INTERCOH '94. Wallingford, England.

Dade, W.B., Nowell, A.R.M., 1992. Moving muds in the marine environment. Coastal sediments '91. ASCE, New York, pp. $54-71$.

Dixit, J.G., 1982. Resuspension potential of deposited kaolinite beds. MSc Thesis, University of Florida, Gainsville, FL.

Grant, J., Daborn, G., 1994. The effects of bioturbation on sediment transport on an intertidal mudflat. Neth. J. Sea Res. $32,63-72$.

Gust, G., Morris, M.J., 1989. Erosion thresholds and entrainment rates of undisturbed in situ sediments. J. Coast. Res. 5, 87-99.

Holland, A.F., Zingmark, R.G., Dean, J.M., 1974. Quantitative evidence concerning the stabilization of sediments by marine benthic diatoms. Mar. Biol. 27, 191-196.

Kuijper, C., Cornelisse, J.M., Winterwerp, J.C., 1989. Research on erosive properties of cohesive sediments. J. Geophys. Res. 94 (C10), 14341-14350.

Maa, J.P.-Y., Wright, L.D., Lee, C.-H., Shannon, T.W., 1993. VIMS Sea Carousel: a field instrument for studying sediment transport. Mar. Geol. 115, 271-287.

Mehta, A.J., Partheniades, E., 1982. Resuspension of deposited cohesive sediment beds. In: Edge, B.L. (Ed.), Proceedings of the 18th International Conference on Coastal Engineering, pp. $1569-1588$

Migniot, C., 1968. Étude des propriétés physiques de différents sédiments très fins et de leur comportement sous des actions hydrodynamiques. Houille Blanche 7, 591-620.

Mitchener, H., Torfs, H., 1996. Erosion of mud/sand mixtures. Coast. Eng. 29, 1-25.

Parchure, T.M., Mehta, A.J., 1985. Erosion of soft cohesive sediment deposits. J. Hydr. Eng. 111, 1308-1326.

Patterson, D.M., 1989. Short-term changes in the erodibility of intertidal cohesive sediments related to the migratory behaviour of epipelic diatoms. Limn. Oceanogr. 34, 223-234.

Schünemann, M., Kühl, H., 1991. A device for erosion-measurements on naturally formed, muddy sediments: the EROMESsystem. GKSS-Forschungszentrum Geesthacht GmbH, Report GKSS 91/E/18, 28 pp.

Tsai, C.-H., Lick, W., 1986. A portable device for measuring sediment resuspension. J. Great Lake Res. 12, 314-321.

Van Rijn, L.C., 1993. Principles of sediment transport in Rivers, Estuaries and Coastal Seas. Aqua Publications, Amsterdam, $658 \mathrm{pp}$.

Verreet, G., Van Goethem J., Viaene, W., Berlamonte, J., Houthuis, R., Berleur, E., 1986. Relations between physicochemical and rheological properties of fine-grained muds. In: Wang, S.Y., Shen, H.W., Ding, L.Z. (Eds.), River Sedimentation III, Mississippi, USA, McNaughton and Gunn, pp. 16371646.

Vos, P.C., De Boer, P.L., Misdorp, R., 1988. Sediment stabilization by benthic diatoms in intertidal sandy shoals; qualitative and quantitative observations. In: De Boer, P.L. (Ed.), Tide-influenced sedimentary environments and facies. Reidel, Dordrecht, pp. 511-526.

Williamson, H.J., 1994. Recent Field Measurements of erosion shear stress using ISIS. 4th Nearshore and Estuarine Cohesive 
Sediment Transport Conference INTERCOH '94. Wallingford, England.

Winterwerp, J.C., 1989. Flow induced erosion of cohesive beds, a literature survey. Cohesive Sediments, Report 25, Delft Hy- draulics, $52 \mathrm{pp}$.

Young, R.A., 1976. Seaflume: a device for in-situ studies of threshold erosion velocity and erosional behaviour of undisturbed marine muds. Mar. Geol. 23, 11-18. 